\title{
Clinical Outcomes after Biologic Graft Use for the Creation of Blalock-Taussig Shunt in Critically Ill Patients with Thrombophilia
}

\author{
Davut Azboy, MD, Zeki Temiztürk, MD \\ Department of Cardiovascular Surgery, The Health Science University, Elazig Research and Training Hospital, Elazig, Turkey
}

\section{ABSTRACT}

Background: The modified systemic to pulmonary artery shunt (mSPS) is an effective palliative procedure in children with cyanotic congenital heart disease (CCHD) who are not suited for total correction. Early graft failure related to hereditary thrombophilic disorder is one cause of mortality. The aim of this study is to compare the clinical outcomes and rate of graft failure after mSPS in cyanotic infants with hereditary thrombophilia using bovine mesenteric venous graft (BMVG) and polytetrafluoroethylene (PTFE).

Methods: 60 cyanotic patients (28 neonates, mean age 19 \pm 11.3 days; range 1 to 27$)$ who had thrombophilic risk factors were divided into 2 groups: BMVG $(n=30)$ and PTFE $(n=30)$. Preoperative thrombophilic factors were measured for each patient. The most common thrombophilic factors were protein $\mathrm{C}$ and $\mathrm{S}$ deficiency and Factor V Leiden mutation. We also investigated D-dimer, positivity of prothrombin G20210A, factor XII and antithrombin III deficiency, and homocysteinemia in both groups. The mean age of patients was $4.6 \pm 1.09$ months (range 1 day to 6 months) in the BMVG group and $3.9 \pm 1.02$ months (range 2 days to 9 months) in the PTFE group $(P=.67)$. mSPS procedures were performed via left thoracotomy $(n=19$ in the BMVG group and $n=22$ in the PTFE group) or right anterior thoracotomy ( $n=3$ in the BMVG group and $n=3$ in the PTFE group). Median sternotomy was performed to create a central shunt in 8 neonates in the BMVG group. In the PTFE group, we performed a central shunt in 5 patients via median sternotomy. Low molecular weight heparin in combination with acetylsalicylic acid (aspirin) were administered after surgery in both groups. The patients received aspirin combined with warfarin (Coumadin) after being discharged from hospital. We performed revision surgery to observe whether any patient had a significant drop in saturation with inaudible mSPS murmur.

Results: 7 patients died early after surgery ( $n=2$ in the BMVG group [6.6\%] and $\mathrm{n}=5$ in the PTFE group [16.5\%]; $P=.022) .53$ patients were discharged home in good clinical condition. Early graft thromboses were observed in 2 patients in the BMVG group $(6.6 \%)$ and 8 patients in the PTFE group $(26.6 \%)(P=.001)$. In a case from the BMVG group, the reason for graft thrombosis was entanglement

Received October 1, 2019; received in revised form August 10, 2020; accepted August 19, 2020.

Correspondence: Abmet Feyzi Abacilar, Division of Cardiac Surgery, Sifa University Medical Faculty, Izmir, Turkey (e-mail: afeyziabacilar@gmail.com). of the graft. Revision surgery was performed successfully without any complication. Cil et collegues has been reported a successful percutaneous balloon angioplasty after an acute thrombosis of BMVG previously [Cil 2010]. In another patient who had acute BMVG thrombosis, we performed transluminal graft angioplasty using successful thrombolytic administration in the catheterization laboratory. There were no complications due to graft materials such as hematoma, seroma, or infection in the BMVG group. Bleeding from the needle hole was seen in 1 patient in the BMVG group. PTFE thrombosis developed in 3 patients within 24 hours $(10 \%)$. We detected total or partial PTFE graft thrombosis in 5 patients during the followup period (20\%). Revision surgeries in 3 patients were performed immediately after diagnosis. Transluminal balloon angioplasty combined with thrombolysis was performed in infants with partial or total PTFE occlusion in 5 patients. In the PTFE group, perigraft seroma $(n=5[16.6 \%)]$ and hematoma $(n=2[6.6 \%])$ were detected. We performed revision surgery because of bleeding from the needle hole in 3 patients in the PTFE group (10\%) in the early period after surgery. We detected a graft infection in 1 patient $(3.3 \%)$ 6 months after surgery in the PTFE group. The rate of overall complications including pseudoaneurysm, seroma formation, graft infection, or partial or total graft occlusion in the early and follow-up periods was $6.6 \%$ in the BMVG group and $53.3 \%$ in the PTFE group $(P$ $=.0001)$. The rate of freedom from shunt failure was

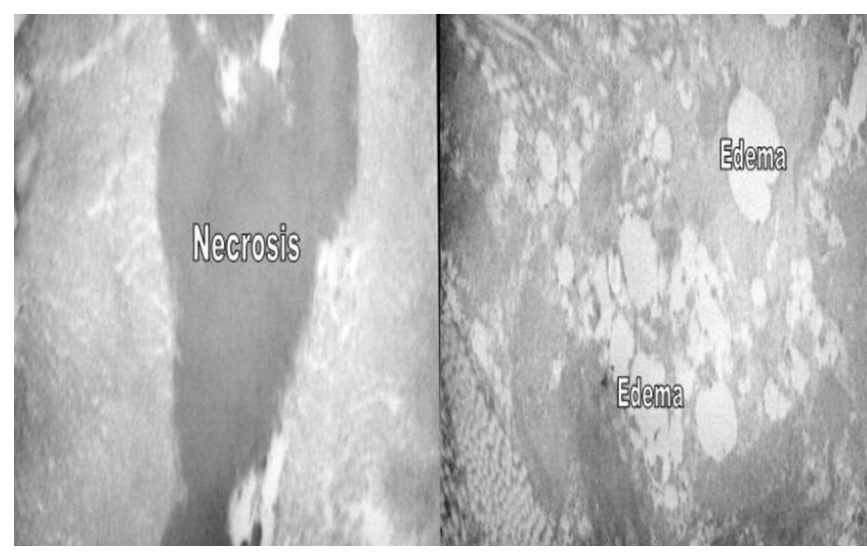

Figure 1. Electron microscopic examination demonstrates subadventitial necrosis (a) and intercellular edema (b). The figure shows subintimal vacuolization and intercellular severe edema in a thrombosed BMVG. 


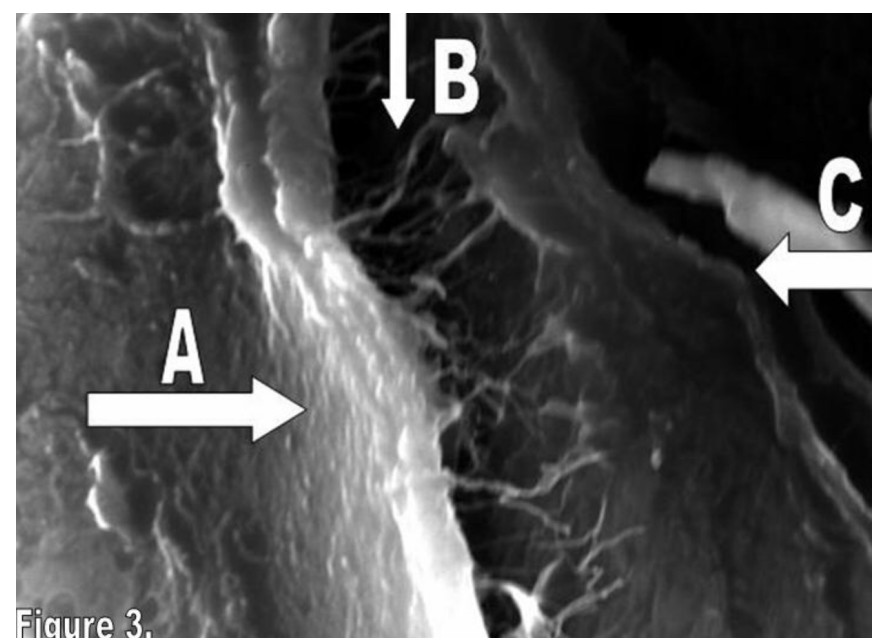

Figure 2. 3-Dimensional electron microscopic examination of a thrombosed BMVG using a vascular clamp. Arrows A, B, and C show adventitia, intima and media, and thrombosed lumen, respectively. The figure shows an abnormally fibrillar formation and separation of graft layers due to vascular clamping and subendothelial necrosis.

$92.6 \% \pm 2.1 \%$ and $76.2 \% \pm 4.8 \%$ during follow-up in BMVG and PTFE groups, respectively $(P=.034)$. The rate of shunt-related mortality was $10.7 \%(\mathrm{n}=3)$ in the BMVG group and $20 \%$ in the PTFE group $(P=.01)$. Regular physical examinations, transcutaneous oxygen saturation, and echocardiographic study were performed for shunt control during follow-up. Shunt occlusion or thrombosis was not seen in the BMVG group; 5 patients in the PTFE group (20\%) had shunt occlusion during follow-up $(P=.001)$.

Conclusion: Our study shows that BMVG, as a biological material, may be used as an alternative material for creating mSPS. It decreases postoperative life-threatening complications after shunt procedures, including graft thrombosis, bleeding from the needle hole, perigraft hematoma, and seroma in patients with hereditary thrombophilia. To our knowledge, we report the first clinical comparison of the 2 grafts in our case series with thrombophilic risk factors.

\section{INTRODUCTION}

Systemic to pulmonary shunt has proven to be highly effective for the palliation of patients with cyanotic congenital heart disease (CCHD) who are not suited for complete repair. However, shunt thrombosis may occur in the early period after surgery or at clinical follow-up before the optimal time for definitive repair [Motz 1999; Alkhulaifi 2000]. Intraluminal calcification and myofibroblastic proliferation after use of polytetrafluoroethylene (PTFE) or Gore-Tex material has been defined in previous publications [Tomizawa 1998; Bove 1997].

For diagnosis of hereditary thrombophilia, we investigated factor $\mathrm{V}$ Leiden mutation; protein $\mathrm{C}$ and $\mathrm{S}$ deficiency; fibrinogen; homocysteine; antithrombin III; factors II, VII, VIII, and IX; and anti-phospholipid antibodies. According
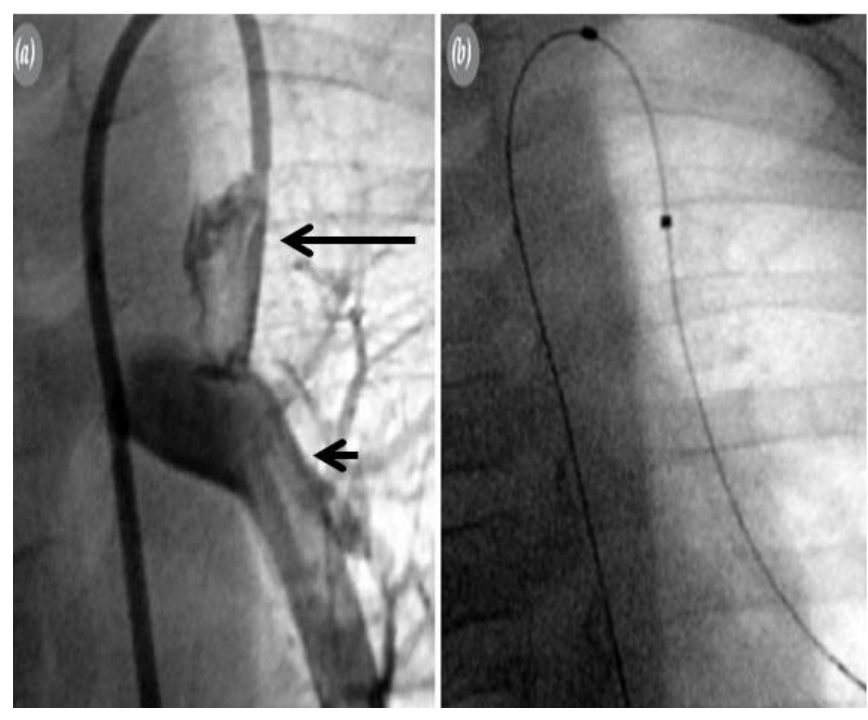

Figure 3. Angiographic documentation shows probed BMVG with a 4-French catheter (a) and 0.045-inch angled guidewire across to the left pulmonary artery before balloon dilatation (b).

to previous reports, we investigated anticardiolipin antibodies, lupus anticoagulant, and prothrombin G20210A mutations in all patients [Akbulut 2008; Simsic 2002; Ergul 2015]. Authors have also suggested that patients with single ventricle [Tomizawa 1998], perioperative platelet transfusion [Bove 1997], and graft size $\leq 4 \mathrm{~mm}$ [Akbulut 2008] increase the risk of shunt thrombosis. In contrast, some investigations [Simsic 2002; Ergul 2015] have suggested that type and size of the graft material for the creation of modified systemic to pulmonary artery shunt (mSPS) and the type of heart pathology have no influence on morbidity or mortality after shunt placement. To prevent severe complications after mSPS, some authors have suggested biologic grafts such as internal thoracic artery [Cobanoglu 1984], umbilical vein [Leao 1985], saphenous vein [Tam2001], and bovine mesenteric venous graft (BMVG) (Pro-Col@) [Akbulut 2008; Kalangos 2001]. The mortality rate after shunt procedures in infants and neonates with a single ventricle has been reported to be $\sim 15 \%$; in patients with 2 ventricles, it is $3 \%$ to $5 \%$ [Kiran 2017; Dogan 2005].

Our previous publications showed that perigraft seroma, pseudoaneurysm, or hematoma as another problem could be seen after PTFE use in shunt procedures [Dogan 2005; Demircin 2004]. A limited number of studies have examined the importance of thrombophilic risk factor positivity as a reason for graft thrombosis in patients who have undergone mSPS [Akbulut 2008; Simsic 2002; Ergul 2015]. We have used bovine mesenteric venous graft (BMVG) as a biologic graft in mSPS operations in some consecutive patients with thrombophilic factors between 2005 and 2019.

The purpose of this study was to investigate the patency rate of bovine mesenteric vein graft (ProCol®) after mSPS in 30 patients with hereditary thrombophilia. We also compare the clinical results and patency rates of biologic and PTFE graft in cyanotic infants. 


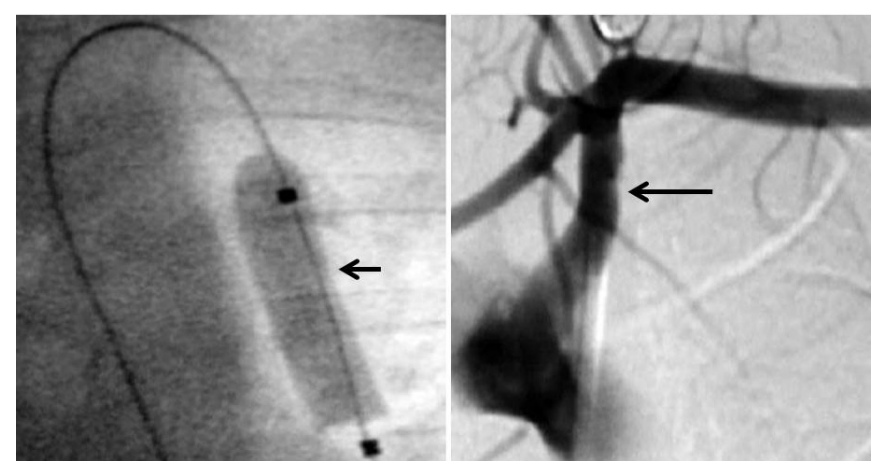

Figure 4. A $4 \times 20-\mathrm{mm}$ balloon across the thrombosed BMVG and inflation along the shunt at $6 \mathrm{~atm}$. We performed second and third inflations distally at $4 \mathrm{~atm}$ (a). After dilatation, an angiogram of the subclavian artery demonstrates blood flow in the shunt, with a thrombus extending through the length of the BMVG (b).

\section{METHODS}

We have been using bovine mesenteric venous graft or PTFE to create mSPS in consecutive cyanotic infants. In preoperative period, we routinely record partial thromboplastin time (PTT), international normalized ratio (INR), and hereditary thrombophilia in cyanotic patients. After receiving approval from the hospital ethics committee, informed consent was received from patients' parents. This study included 60 cyanotic infants (40 male) with thrombophilic risk factors who underwent $\mathrm{mSPS}$. The patients were divided into 2 groups: BMVG in 30 patients and PTFE in the other 30. The mean age of neonates was $19 \pm 11.3$ days (range 1 to 27 days). Preoperative thrombophilic factors were measured in each patient. The most common thrombophilic factors were protein $\mathrm{C}$ and $\mathrm{S}$ deficiency ( $\mathrm{n}=12$ in BMVG group and $\mathrm{n}=9$ in PTFE group) and Factor V Leiden mutation $(\mathrm{n}=4$ in BMVG group and $\mathrm{n}=2$ in PTFE group). We also investigated D-dimer, positivity of prothrombin G20210A, factor XII and antithrombin III deficiency, and homocysteinemia ( $\mathrm{n}=6$ in BMVG group and $\mathrm{n}=7$ in PTFE group).

28 patients were neonates ages 5 to 23 days, mean body weight was $3.1 \pm 0.8 \mathrm{~kg}$. To prevent the distortion of pulmonary arteries and an equal pulmonary blood flow in infants with small-diameter pulmonary arteries, we preferred a central shunt via midline sternotomy incision. In patients with suitable pulmonary artery diameter, shunt procedures were performed via left thoracotomy or right anterior thoracotomy incision. Median sternotomy was performed to create a central shunt in 8 neonates in the BMVG group. In the PTFE group, we performed a central shunt in 5 patients via median sternotomy. An mSPS was constructed under cardiopulmonary bypass (CPB) because of a high risk of severe intraoperative arrhythmia and severe hypoxia during pulmonary artery clamping. In these patients, an aortic and a single venous cannulation was performed. Before the initiation of normothermic $\mathrm{CPB}, 3 \mathrm{mg} / \mathrm{kg}$ heparin was administered. In the remaining patients, procedures were performed through the left
Table 1. Preoperative patient characteristics and cardiac pathology of both groups

\begin{tabular}{|c|c|c|c|}
\hline Characteristic & $\begin{array}{l}\text { BMVG Group } \\
(\mathrm{n} \%)\end{array}$ & $\begin{array}{l}\text { PTFE Group } \\
\quad(\mathrm{n} \%)\end{array}$ & $P$ \\
\hline Age (mo) & $13.6 \pm 12.1$ & $16.1 \pm 11.9$ & .76 \\
\hline $\operatorname{Sex}(M / F)$ & $19 / 11$ & $21 / 9$ & .55 \\
\hline Weight (g) & $3655 \pm 1120$ & $2980 \pm 980$ & .56 \\
\hline Neonates & 15 & 13 & .67 \\
\hline \multicolumn{4}{|l|}{ Cardiac pathology } \\
\hline $\begin{array}{l}\text { Single ventricle + pulmonary } \\
\text { atresia }\end{array}$ & 14 & 11 & \\
\hline Truncus arteriosus & 2 & 5 & \\
\hline $\begin{array}{l}\text { Double outlet right ventricle + } \\
\text { pulmonary atresia }\end{array}$ & 3 & 2 & \\
\hline $\begin{array}{l}\text { Single atrium, Single ventricle, } \\
\text { pulmonary atresia, major aorto- } \\
\text { pulmonary collateral arteries }\end{array}$ & 1 & 1 & \\
\hline $\begin{array}{l}\text { Transposition of great arteries }+ \\
\text { pulmonary atresia }\end{array}$ & 2 & 5 & \\
\hline $\begin{array}{l}\text { Tetralogy of Fallot + pulmonary } \\
\text { atresia }\end{array}$ & 5 & 5 & \\
\hline $\begin{array}{l}\text { Ventricular septal defect + pulmo- } \\
\text { nary atresia }\end{array}$ & 3 & 1 & \\
\hline
\end{tabular}

Data are mean \pm SD: Standard deviation; BMVG: Bovine mesenteric venous graft; PTFE: Polytetrafluoroethylene

or right thoracotomy. In thoracotomy groups, we administered intravenous heparin at a dose of $2 \mathrm{mg} / \mathrm{kg}$ before the initiation of anastomosis.

\section{Preparation of BMVG}

We [Akbulut 2008] and Kalangos [2001] have described BMVG preparation in previous publications. Briefly, before the construction of the modified Blalock-Taussig shunt, the Dacron mesh covering BMVG is removed from the specially designed cab. BMVG is rinsed in 2 basins, each containing 1 liter of saline solution, for a minimum of 5 minutes, and then placed into a third basin containing $500 \mathrm{~mL}$ of sterile saline and 20,000 IU heparin, for a minimum of 5 minutes. During this rinsing procedure, the lumen is irrigated using a syringe in the indicated direction with $\geq 100 \mathrm{~mL}$ of the solution.

\section{Surgery}

Median sternotomy or thoracotomy was performed. The thymus was totally resected. In the sternotomy group, we opened the pericardium, and a stay suture was inserted for pericardial suspension. The aorta, brachycephalic artery, and main and branch pulmonary arteries were circled. If there was a patent ductus arteriosus, it was encircled. When we used extracorporeal circulation, patent ductus arteriosus was 
Table 2. Thrombophilic factor levels in both groups

\begin{tabular}{lccc}
\hline Factor & BMVG Group & PTFE Group & $P$ \\
\hline Factor VIII & $236.1 \pm 136.1$ & $267.5 \pm 111.7$ & .66 \\
Factor IX & $212.8 \pm 170.2$ & $196.3 \pm 19.2$ & .56 \\
Factor II & $133.0 \pm 99.4$ & $144.7 \pm 18.9$ & .63 \\
Protein C & $94.5 \pm 47.0$ & $92.9 \pm 56.1$ & .76 \\
Protein S & $63.9 \pm 34.9$ & $78.2 \pm 26.2$ & .72 \\
Activated protein C resistance & $11(36.6)$ & $15(50)$ & .56 \\
Factor V & $107.2 \pm 36.9$ & $114.6 \pm 59.2$ & .85 \\
Factor VII & $261.2 \pm 96.7$ & $189.5 \pm 84.3$ & .70 \\
Factor X & $109.2 \pm 36.1$ & $104.7 \pm 27.5$ & .64 \\
Factor XI & $176.0 \pm 73.7$ & $185.9 \pm 65.4$ & .96 \\
Factor XII & $119.2 \pm 47.9$ & $143 \pm 38.3$ & .72 \\
Antithrombin III & $136.0 \pm 55.7$ & $144.8 \pm 47.1$ & .86 \\
von Willebrand factor & $209.0 \pm 78.4$ & $246.3 \pm 62.4$ & .55 \\
Homocysteine & $9.8 \pm 3.1$ & $11.1 \pm 4.3$ & .86 \\
Factor V Leiden & $7(23.3)$ & $9(30)$ & .56 \\
PG20210A mutation & $8(26.6)$ & $11(36.6)$ & .54 \\
\hline
\end{tabular}

Data are mean \pm SD: Standard deviation; BMVG: Bovine mesenteric venous graft; PTFE: Polytetrafluoroethylene.

closed. We observed blood oxygen saturation for 2 to 3 minutes before the pulmonary artery was clamped. To prevent desaturation and severe hypotension in infants, we performed the central shunt under normothermic CPB in 13 neonates (n $=8$ in BMVG group and $n=5$ in PTFE group). Anastomosis was performed using $6 / 0$ polypropylene suture. During the anastomosis of BMVG, special care was taken to avoid grasping the bovine mesenteric vein graft with forceps. Heparin was neutralized after the procedures. To prevent early graft thrombosis due to thrombophilia or surgery itself, antiaggregant and low molecular weight heparin $(\mathrm{LMWH})$ were administered in the intensive care unit (ICU) in both groups.

\section{Statistical Analysis}

Data were analyzed using SPSS 19 (Chicago, IL). Age and weight are expressed as median. Operative complications and mortality are shown as percentages and all variables mean \pm standard deviation (SD). Nominal data with Gaussian distribution were compared using analysis of variance and nonGaussian parameters with Kruskal-Wallis test. Chi-squared test was used to compare categorical variables.

\section{RESULTS}

In the BMVG group, two patients developed shunt failure in the early postoperative period. The first case was a neonate who underwent mSPS via left thoracotomy. We used
Table 3. Postoperative complications early and at 1-year follow-up in both groups

\begin{tabular}{|c|c|c|c|}
\hline Complication & BMVG Group & PTFE Group & $P$ \\
\hline \multicolumn{4}{|l|}{ Early } \\
\hline Graft thrombosis & $2(6.6)$ & $8(26.6)$ & $.001 *$ \\
\hline Perigraft seroma & 0 & $5(16.6)$ & $.001 *$ \\
\hline Hematoma & 0 & $2(6.6)$ & $.034 *$ \\
\hline Bleeding & 0 & $3(10.6)$ & $.01 *$ \\
\hline Graft infection & 0 & $1(3.3)$ & .34 \\
\hline \multicolumn{4}{|l|}{ 1-Year follow-up } \\
\hline Graft thrombosis & $2(7.1)$ & $6(24)$ & $.001 *$ \\
\hline Perigraft seroma & 0 & $2(6.6)$ & .034 \\
\hline Hematoma & 0 & 0 & \\
\hline Bleeding & 0 & 0 & \\
\hline Death, early & $2(6.6)$ & $5(16.6)$ & $.022 *$ \\
\hline Death, 1-year & $4(17.3)$ & $5(20)$ & .56 \\
\hline \multicolumn{4}{|l|}{ Cause of death } \\
\hline Graft failure & 0 & 5 & $.001 *$ \\
\hline Sepsis & 1 & 1 & .89 \\
\hline Renal failure & 1 & 1 & .76 \\
\hline Multiorgan failure & 0 & 1 & .55 \\
\hline \multicolumn{4}{|c|}{ Combined early and follow-up } \\
\hline Graft thrombosis & $4(17.8)$ & $14(56)$ & $.0001 *$ \\
\hline Perigraft seroma & 0 & $7(28)$ & $.0001 *$ \\
\hline Hematoma & 0 & $2(6.6)$ & $.022 *$ \\
\hline Bleeding & 0 & $3(10.6)$ & $.002 *$ \\
\hline
\end{tabular}

Data are mean \pm SD: Standard deviation; BMVG: Bovine mesenteric venous graft; PTFE: Polytetrafluoroethylene.

*Significant at $P<.05$.

a vascular clamp for bleeding control during the operation, and the patient underwent a shunt revision immediately. In the revision, the graft was removed, and the shunt procedure was performed again. We took a sample from the graft for microscopic examination. Electron microscopic examination demonstrates subadventitial necrosis (a) and intercellular edema (b). The figure shows subintimal vacuolization and severe intercellular edema in a thrombosed BMVG (Figure 1). There was a separation of the intima, and medial layer using an electron microscopic examination of a thrombosed BMVG (Figure 2). There was an abnormally fibrillar formation and separation of graft layers due to vascular clamping and subendothelial necrosis (Figure 2). Thus, we did not use vascular clamp in the remaining patients in the BMVG group. The BMVG shunt material was occluded with the pressure of the fingers or bulldog clamp. After the operation, the antiplatelet regimen (aspirin) and anticoagulation (unfractionated 
heparin) were restarted. Heparin was stopped six days after the operation, but antiaggregant therapy continued in the clinical follow-up.

In the second case, graft kinking was the cause of the BMVG thrombosis (Figure 3). The graft was shortened from the pulmonary side, embolectomy was performed, and the graft was rinsed in a heparinized saline solution. It was anastomosed to the pulmonary artery after the procedure, and antiaggregant therapy and anticoagulation were started. After the second procedure, however, early graft failure was detected by echocardiography. Because the third operation might cause lifethreatening results, this patient underwent transcatheter balloon angioplasty. The procedure was successfully performed in the catheterization laboratory (Figure 4). Treatment was completed without any complication, and thrombolytic therapy started. After the thrombolytic treatment, antiaggregant and heparin administration continued. Five days later, anticoagulation was stopped, and the antiplatelet regimen continued. The postoperative course was uneventful, and the patient was discharged from the hospital with the administration of aspirin. There was no bleeding from needle stitches during the operations and no sign of complication regarding the shunt procedure such as seroma, excessive mediastinal drainage, hematoma, or infection. To date, no complications such as graft failure or thrombosis were detected at follow-up by clinical and transthoracic echocardiographic examination. All shunts were patent and functioning well after an average follow-up time of 10.5 months, despite the lack of postoperative antiplatelet and anticoagulation regimens except in the 2 cases described above. Complications after surgery in the early time and follow-up period are summarized in Table 3.

\section{DISCUSSION}

Modified systemic to pulmonary shunt is used as an effective palliative method in patients with CCHD. Unfortunately, life-threatening complications such as shunt failure may occur in the early or late postoperative period. In the previous reports, risk factors such as smaller shunt size and neonatal age have been described [Kiran 2017; McKenzie 2013; Şişli 2019; Dogan 2005]. In a small number of reports, thrombophilic factor positivity has been defined as a cause of shunt thrombosis [Akbulut 2008; Simsic 2002; Ergul 2015]. The rate of shunt thrombosis has been described as 12\% [Demircin 2004; Katzman 2005]. Histopathologic research has demonstrated that the rate of shunt thrombosis is $25 \%$ to $50 \%$ of patients within 8 months after surgery [Glickman 2004]. To prevent early shunt failure, the use of aspirin or heparin has been suggested to prevent shunt thrombosis [Akbulut 2008; Simsic 2002; Ergul 2015; Cobanoglu 1984; Leao 1985; Tam 2001; Kalangos 2001; Kiran 2017; McKenzie 2013; Şişli 2019]. In addition, biologic grafts such as internal thoracic artery [Cobanoglu 1984], umbilical vein [Leao 1985], and saphenous vein [Tam 2001] have been used successfully in mSPS.

The aim of this study was to examine the primary patency rate of BMVG in cyanotic patients with hereditary thrombophilia.
We compared clinical outcomes and shunt failure after the use of synthetic and biologic graft use. Our study findings show that the use of antiplatelet regimens with or without anticoagulant agents did increase the patency rate of mSPS after the use of BMVG in cases with hereditary thrombophilia. Only 2 cases required revision surgery in the early period after surgery in the BMVG group, whereas 8 patients needed revision in the PTFE group. This was statistically significant.

Regular physical examinations, transcutaneous oxygen saturation, and echocardiographic study were performed for shunt control during follow-up in both groups. There were no complications due to graft material such as hematoma, seroma, or infection in the BMVG group. Bleeding from the needle hole was seen in only 1 patient in the BMVG group. Early graft thrombosis developed in 3 PTFE group patients $(10 \%)$ within 24 hours. Transthoracic echocardiography showed total or partial PTFE graft thrombosis in 8 patients in the ICU or during follow-up. Revision surgeries in 3 patients were performed immediately after diagnosis. Transluminal balloon angioplasty combined with thrombolysis was performed in infants with partial or total PTFE occlusion in 5 patients. In the PTFE group, perigraft seroma $(16.6 \%)$ or hematoma $(6.6 \%)$ were seen. We performed revision surgery because of bleeding from the needle hole in 3 patients in the PTFE group (10\%) in the early period after surgery. Graft infection has been detected in 1 patient 6 months after surgery in the PTFE group. Therefore, overall complications such as pseudoaneurysm, seroma formation, graft infection, or partial or total graft occlusion in the early period after surgery and the follow-up period were $6.6 \%$ in the BMVG group and $53.3 \%$ in the PTFE group. Freedom from total or partial shunt failure during follow-up was $92.6 \%$ $\pm 2.1 \%$ in the BMVG group and $76.2 \% \pm 4.8 \%$ in the PTFE group. The rate of shunt-related mortality and morbidity was significantly higher in the PTFE group. Shunt occlusion was seen in 2 patients in the BMVG group and 6 patients in the PTFE group during follow-up.

We believe that perfecting shunt conduits for creating mSPS in cyanotic patients with thrombophilic risk factors may be the first important issue for solution of some lifethreatening problems in these patients. A high level of thrombophilic factor positivity seems to be the reason for shunt thrombosis, and it can be fatal, especially in neonates. To prevent severe complications, we have to decide on different strategies such as graft material according to patient characteristics.

Another important issue is postsurgery management. In these patients, we started heparin (LMWH) in the ICU if the amount of mediastinal bleeding was $<3$ to $4 \mathrm{~mL} 6$ hours after the surgery and the PTT was $<40$ seconds. We started aspirin routinely after extubation $(3 \mu \mathrm{g} / \mathrm{kg}$ once daily). If there was a significant drop in blood oxygen saturation with an inaudible murmur and deterioration despite intense medications, we preferred immediate surgical or percutaneous interventions in the operating room or catheterization laboratory.

As we know, cyanotic cases tend to hypercoagulopathy. It is clear that additional risk factors, such as protein $\mathrm{C}$ or $\mathrm{S}$ deficiency and factor $\mathrm{V}$ Leiden mutation, may increase postoperative graft or pulmonary artery thrombosis. According 
to our study, BMVG may be decisive to decrease postsurgery shunt failure.

PTFE, usually Dacron, and Gore-Tex grafts have small pore size that allows fibroblastic incorporation to bind it to surrounding structures. Thus, it is difficult to release from the surrounding tissue in complete repair of cardiac defects. In addition, serious fluid leakage (oozing) from synthetic grafts may increase hospitalization time. Massive hemoptysis has been reported from pseudoaneurysm formation after the use of synthetic grafts. Perigraft seroma or hematoma as severe complications may be seen early after PTFE use in surgery. We did not detect seroma or hematoma in BMVG in our case series. To provide the best clinical results, some surgeons have used biologic grafts, such as umbilical vein by Akbulut [2008] and Leao [1985] or saphenous vein graft by Tam [2001]. To create mSPS, internal thoracic artery as a biologic conduit has been reported by Cobanoglu [1984].

The use of BMVG as a bioprosthesis is not a new concept. Authors have reported BMVG use successfully in hemodialysis access [Katzman 2005; Glickman 2004] and patients with peripheral arterial disease [Schmidli 2004; Hatzibaloglu 2004]. According to clinical outcomes after the use of BMVG in hemodialysis access, authors proposed it to be a safe alternative to synthetic graft [Schmidli 2004]. The use of BMVG in neonates has been reported in a limited number of patients by Kalangos [2001] and Akbulut [2008] without the use of antiaggregant. No investigation has reported about hereditary thrombophilia in these publications, except the study by Akbulut [2008]. Ergul [2015] suggested the investigation of thrombophilia factors in patients with CCHD before mSPS. They detected some thrombophilic factors in 3 of 8 patients with shunt thrombosis in the early postoperative period.

Our recent clinical experience shows that the use of BMVG requires special care during surgery. We suggest avoiding the use of classic vascular clamping, which may cause separation of BMVG vascular layers. Kalangos [2001] and Akbulut [2008] showed perfect BMVG patency rate without the use of anticoagulant and antiaggregant administration in the early as well as late postoperative period. Because all our patients had thrombophilia, we used antiaggregant and/or anticoagulant without any complication. Cil et collegues has been reported a successfull percutaneous balloon angioplasty after an acute thrombosis of BMVG previously [Cil 2010].

To our knowledge, this study describes the largest case series of BMVG used for creating mSPS in infants and neonates. We also compared the first clinical results after the use of PTFE and BMVG in early and mid-term findings in CCHD with hereditary thrombophilia. We believe that BMVG may be an alternative conduit for shunt procedures, especially in risky patients, without perigraft seroma or hematoma formation as rare but life-threatening complications with prolonged hospitalization. As we use biological graft material, we believe that there will be less graft obstruction in the mid- and longterm period until total correction surgery. In addition, the surgical technique is easy; but it should be kept in mind that special care has to be taken to avoid grasping the BMVG with forceps and it should never be clamped. If necessary it may be occluded with pressure of the fingers or a bull-dog clamp, which may damage the intimal or medial layer of the graft.

\section{Conclusion}

The measurement of thrombophilic risk factors before mSPS is important to inhibit intraluminal thrombosis despite the administration of anticoagulation and antiplatelet therapy. Bovine mesenteric vein graft seems to be an alternative conduit in shunt procedures. We suggest special care during graft anastomosis to avoid damage to vascular layers. Antiaggregants or anticoagulants may be used in high-risk patients undergoing systemic to pulmonary shunt. Although absence of bleeding, hematoma, and infection is a superior feature of BMVG, we need a randomized clinical study in the future. If necessary it may be occluded with pressure of the fingers or a bull-dog clamp, which may damage the intimal or medial layer of the graft. Cil [2004] has been reported a successfull percutaneous balloon angioplasty after an acute thrombosis of BMVG previously.

\section{ACKNOWLEDGEMENTS}

The authors would like to thank Prof. Dr. Omer Faruk Dogan, Dr. Feyzi Abacilar, and Dilek Kizikli Dogan to support the study design, performing the surgery, and valuable scientific edition, postoperative managements of the patients' nutrition and dietary management postoperatively.

\section{REFERENCES}

Akbulut B, Dogan OF, Guvener M, Yilmaz M, Yorgancioglu C, Karagoz $\mathrm{T}$, et al. 2008. Bovine mesenteric venous graft as an alternative conduit in patients with cyanotic heart disease with E-polytetrafluoroethylene graft failure caused by thrombophilic factor positivity after modified BlalockTaussig shunt. Heart Surg Forum 11:37-41.

Alkhulaifi AM, Lacour-Gayet F, Serraf A, Belli E, Planche C. 2000. Systemic pulmonary shunts in neonates: Early clinical outcome and choice of surgical approach. Ann Thorac Surg 69:1499-1504.

Bove EL, Kohman L, Sereika S, et al. 1997. The modified BlalockTaussig shunt: Analysis of adequacy and duration of palliation. Circulation 76(suppl 3):19-23.

Cil N, Dogan OF, Karagoz T, Dogan R. Successful percutaneous transluminal balloon angioplasty and thrombolysis of a thrombosed bovine mesenteric venous graft after a modified Blalock-Taussig shunt. Turkish J Thorac Cardiovasc Surg;18(3):225-228

Cobanoglu A, Abbruzzese P, Brauner D, Ferre B, Issenberg H, Starr A. 1984. Therapeutic considerations in congenital absence of the right pulmonary artery. Use of internal mammary artery as a preparatory shunt. J Cardiovasc Surg 25:241-245.

Demircin M, Dogan R, Ozkan M, Ozsoy F, Kuzgun E, Guvener M. 2004. Perigraft seroma complicating the modified Blalock-Taussig shunts: Two consecutive instances with review of literature. Turk J Pediatr 46:275-278.

Dogan OF, Duman U, Karagoz T, Ozkutlu S, Ersoy U. 2005. Diagnosis of perigraft seroma formation by use of echocardiography after modified Blalock-Taussig shunt. Eur J Echocardiogr 6:385-387. 
Ergul Y, Kiplapinar N, Tanidir IC, Ozturk E, Guzeltas A, Haydin S,Akcay A, Erek E, et al. 2015. Role of thrombophilia factors in acute systemicpulmonary shunt obstruction. Pediatr Int 57:1072-1077.

Glickman MH, Lawson JH, Katzman HE, Schild AF, Fujitani RM. 2004. Challenges of hemodialysis access for high risk patients: Impact of mesenteric vein bioprosthetic graft. J Vasc Accsess 4:73-80.

Hatzibaloglu A, Velissaris I, Kaitzis D, Grakas D, Avdelidou A, Kiskinis D. 2004. ProCol vascular bioprosthesis for vascular access: Midterm results. J Vasc Access 5:16-18.

Kalangos A, Beghetti M, Pache JC, Vala D, Faidutti B. 2001. Systemic to pulmonary artery shunt using a bovine mesenteric venous graft in newborns. J Card Surg 15:239-243.

Katzman HE, Glickman MH, Schild AF, Fujitani RM, Lawson JH. 2005. Multicenter evaluation of the bovine mesenteric vein bioprostheses for hemodialysis access in patients with an earlier failed prosthetic graft. J Am Coll Surg 201:223-230.

Kiran U, Aggarwal S, Choudhary A, Uma B, Kapoor PM. 2017. The Blalock and Taussig shunt revisited. Ann Card Anaesth 20:323-330.

Leao LEV, Andrade JCS, Succi JE, Cueva CC, Ribeiro EE, Carvalho ACC, Buffolo E. 1985. Modified Blalock-Taussig shunt with an umbilical vein graft. Texas Heart Inst J 12:65-71.

McKenzie ED, Khan MS, Samayoa AX, Vener DS, Ishak YM, Santos AB, Heinle JS, Fraser CD Jr. 2013. The Blalock-Taussig shunt revisited: A contemporary experience. J Am Coll Surg 216:699-704.
Motz R, Wessel A, Ruschewski W, Bursch J. 1999. Reduced frequency of occlusion of aorta pulmonary shunts in infants receiving aspirin. Cardiol Young 9:474-477.

Schmidli J, Savolainen H, Heller G, Widmer MK, Then-Schlagau U, Baumgartner I, Carrel TP. 2004. Bovine mesenteric vein graft (ProCol) in critical limb ischaemia with tissue loss and infection. Eur J Vasc Endovasc Surg 27:251-253.

Simsic JM, Uber WE, Lazarchick J, Bradley SM. 2002. Systemic-topulmonary artery shunt thrombosis in a neonate with factor $\mathrm{V}$ Leiden mutation. Ann Thorac Sur 74:2179-2181.

Şişli E, Tuncer ON, Şenkaya S, Doğan E, Şahin H, Ayık MF, Atay Y. 2019. Blalock-Taussig shunt size: Should it be based on body weight or target branch pulmonary artery size? Pediatr Cardiol 40:38-44.

Tam VKH, Murphy K, Parks WJ, Raviele AA, Vincent RN, Strieper M, Cuadrado AR. 2001. Saphenous vein homograft: A superior conduit for the systemic arterial shunt in the Norwood operation. Ann Thorac Surg 71:1537-1540.

Tomizawa Y, Takanashi Y, Noishiki Y, et al. 1998. Evaluation of small caliber vascular prostheses implanted in small children: Activated angiogenesis and accelerated calcification. ASAIO J 44:M496-M500. 